\title{
Challenges Faced by Teachers in Teaching Literacy and Numeracy for Slow Learners
}

\author{
Mumpuniarti ${ }^{1}$ \\ ${ }^{1}$ Special Education, Faculty of Education, Yogyakarta State University, Indonesia \\ Correspondence: Mumpuniarti, Special Education, Faculty of Education, Yogyakarta State University, Indonesia. \\ E-mail: mumpuniarti1@gmail.com
}

Received: December 20, 2016

Accepted: January 23, $2017 \quad$ Online Published: May 31, 2017

doi:10.5539/jsd.v10n3p243

URL: https://doi.org/10.5539/jsd.v10n3p243

\begin{abstract}
The current study explored pedagogical strategies carried out by teachers to support special need children in improving their level of literacy and numeracy. The current study utilized qualitative research design where classroom observations were carried out to explore teaching activities used by teachers in teaching language and mathematics. It was then followed by a focus group discussion to identify problems faced by children in numeracy and literacy. This research was carried out in one of the elementary schools in Yogyakarta, Indonesia. Data collected was analyzed manually by focusing on the main aspects. Results demonstrated that 27 activities were frequently used by teachers in teaching language and mathematics. Those activities are the common teaching practice for slow learners. In order to evaluate the effectiveness of those practices, a focus group discussion with a group of students was carried out. Results revealed that most students have problems in literacy (spelling, reading complex words, and write long words) and numeracy (counting, subtraction, multiplication and divide). As the common teaching practice was found to have minimal effect on children's literacy and numeracy, the current study suggests rethinking of a new pedagogical approach for improving literacy and numeracy for slow learners.
\end{abstract}

Keywords: pedagogical strategy, slow learners, literacy, numeracy, teachers, special need children

\section{Introduction}

Improving literacy and numeracy is the main priority and becomes the national strategy in most of the countries in the world (Quinn, 2011). Many countries introduce various educational plans and pedagogical practices to improve literacy and numeracy. For instance, the Irish Department of Education and Skills has introduced and funded where the set targets to be met by 2020 are really high. In Poland, OECD (2015b) has reported that "Literacy and numeracy skills of 16-65 year olds in Poland are below the average of countries participating in the Survey of Adult Skills, while 16-24 year-olds score above the average in literacy and around the average in numeracy (p.4)". In Indonesia, improving numeracy and literacy rates among people are also the main educational priority (OECD 2015a) has also listed several strategies for improving numeracy and literacy for children in Indonesia. In the late 1990s, most countries realized that improving literacy and numeracy among children has a strong connection with children ability. Since then, the spectrum of research on literacy and numeracy has been expanded into education for special needs. The terms such as learning disabilities and learning difficulties are frequently used in public when discussing numeracy and literacy. In educational context, the majority of scholars believe that pedagogical strategy for special education requires specific approaches and techniques. This is due to learners' diversity in terms of their cognitive levels, emotional development stages and various stages of mental practices. One of the pedagogical strategies used in teaching and learning for children with special needs is a mediation technique. Mediation techniques refer to strategies that integrate all the elements of reading, listening, playing, acting and role playing. Past research also suggest the importance of using modern technological tolls to support learning for children with special needs. Although those suggested strategies are found to be useful, teachers have their preferences to carry out activities that are suited with the children need and school environment. This implies that teachers play a great in teaching school pupils.

\subsection{Problems}

There are few terminologies used in past studies while discussing learning strategies among slow learners such as learning disabilities, learning disorders, intellectual disabilities and learning difficulties. In clinical psychology, 
the term 'mental retardation' is commonly used in researching such problem. It refers to “... a condition of arrested or incomplete development of the mind, which is especially characterised by impairment of skills manifested during the developmental period, which contribute to the overall level of intelligence, i.e. cognitive, language, motor" (Professional Affairs Board of The British Psychological Society, 2000:20). In clinical studies, children with special needs are supposed to be diagnosed in order to identify the condition of their biological conditions either they have mental retardation, partial disorder, cerebral function disorders and etc.

It is relevant to indicate that in psycho-educational research on special needs, those terms interchangeably used. In fact, due to limitation of clinical support in school, students with disabilities are gathered in a classroom for educational-based treatment. The main focus is to help the children in adapting with their life. In an Indonesian context, the term of 'slow learners' are popularly used by teachers as the national curriculum and parents are more likely to focus on academic achievement rather than other aspects. In a situation where the majority of schools used a similar curriculum, education for children with special needs require a specific teaching approach. Although many psychological research suggest specific learning strategies for children with support needs, teachers' competency in carrying out suitable teaching strategies pose a great challenge in teaching profession.

\subsection{Pedagogical Strategies and Special Education}

Pedagogical strategies are commonly defined at three levels namely general instructional designs; teaching and learning unit such as a lesson or a course module; and teaching methods. This definition seems to have a lack of combination two main elements that are teachers' competences in teaching skills and content knowledge. These two elements are integral elements for teaching profession. Discussing the similar concept, some researchers tended to highlight the importance of competences elements and audiences (students or pupils) socio-cultural elements (Ahmad \& Awang, 2016). In the context of special need children, pedagogical strategies require specific measures to ensure the effectiveness of teaching and learning. Indeed, pedagogical strategies are found to be unique in inclusive education.

Teaching children with special needs post a challenge to teaching profession due to the uniqueness of every single child in a classroom. Because of this situation, teaching them require specific training that integrates various pedagogical-skills, pedagogical-knowledge, positive characteristic of teachers, good attitudes and helping skills, as well as subject-content knowledge. Therefore, various pedagogical strategies have been introduced in the past in order to teach, support and guide children to improve their reading and mathematical skills. One of the famous learning models in teaching children with special needs is the Universal Learning Design (ULD). ULD integrates learning theories by taking into account pupils' abilities in thinking, best-practice; and instruction technologies. This integration between theories and practices is essential Meynet (2014) stated that "...importance of bringing together diverse students, families, educators and community members, in order to create schools and other social institutions that are based on respect, acceptance and belonging. Inclusive education recognizes that all students are learners who benefit from a challenging, meaningful, appropriate curriculum ... this implies differentiated instruction techniques that address student's unique strengths and needs (p.35)".

Universal learning design is a lesson plans to help teachers meet the learning needs of students who are new variations on the variations in the use of media, a variety of approaches to students, not tested variations of multi-activity approach and the involvement of learners to act independently arrange learning activities (Rosenblatt, Walker \& McMahon, 2015). Stephanie (2006) stated that “...universal design learning is helpful in teaching and learning that fulfil the needs of slow learners (p.2)”. The universal design learning integrates theoretical-based learning part of brain performance, best-practice; instructional technologies as well as the underlying principle of all students for successful learning. Puccini, Puccini and Chang (2013) suggest that the ULD is supposed to be planned and carried out systematically. It has at least seven elements of utilizing ULD in teaching numeracy and numeracy for children with special needs. Firstly, delivering knowledge and information for special needs children is supposed to be carried out carefully as they have different abilities. They also have various support needs. Secondly, short period of teaching seems to be effective in teaching special need children in order to encourage their participation in lesson activities. Thirdly, prioritizing concrete ideas instead of abstract may help them to improve their numeracy and literacy skills. Past research suggest that special need children tend to be more interested in concrete-based learning. Fourthly, remedial teaching is supposed to be carried out professionally in order to ensure pupils learn something from mistakes. Fifthly, fun learning is essential in teaching literacy and numeracy. Sixthly, teachers' abilities to prioritize things in lesson will help children to optimize understanding in learning various subjects. Finally, systematic pedagogical teaching strategies help children to obtain numeracy and literacy skills steadily. Although ULD provides detailed list of teaching numeracy and literacy for special need children, to what extent the teachers are able to carry out all the 
suggested steps require further field work research.

\subsection{Inclusive Education as a Pedagogical Strategy to Improve Literacy and Numeracy}

Past research showed that the majority of slow learners are found to have problems cognitively but they are doing well in social interaction. One of the problems faced by these children is regarding their lack of confidence to involve in academic activities. This increases their inferiority complex. This is because the majority of their friends in public elementary have a better academic achievement. This also affects their self-actualization in academic areas. This problem needs to be solved by teachers, especially by primary school teachers who have identified the problems at the beginning level. Then it has to be solved by teachers in secondary schools as well as in home (Ahmad \& Awang 2016). This highlights the importance of inclusive education in order to uphold human rights and democracy, as well as to meet the demands of a multicultural education, justice (equity), and equality (equality). According to Berns (2004:) “... inclusion is the educational philosophy of being of part of the whole ... that children are entitled to fully participate in their school and community (p.227)”. This indicates that inclusive education is a worldwide concept, and children are supposed to participate fully in school and society. The importance of inclusive education has been clearly stated in the Law of the Republic of Indonesia (Number 19, 2011) on the Convention on the Rights of Persons with Disabilities. Steven Shaw, Darlene Grimes, Jodi Bulman (2005) stated that special needs children including “... slow learners who are doing poorly in school, yet are not eligible for special education (p.11)". Slow learners are also labelled as mentally illness students (borderline mentally retarded) in public and media. Malik (2009:61) stated that slow learners “... are generally slower to 'catch on' to whatever is being taught if it involves symbolic, abstract or conceptual subject matter (p.61)". Furthermore, Malik (2009) suggests that they also have the characteristics of lacking concentrations, less survive in abstract thinking. It resulted in difficulties to achieve the learning outcomes in accordance with the achievements of peer age group. Slow learners have problems to comprehend symbols and abstract concepts. Slow learners often do better in non-academic subjects in school. It implies that they require mediation model of learning with concrete learning resources. Sugapriya and Ramachandran (2011) stated that computer animations may be as an appropriate strategy of learning for slow learners. Past study shows that slow learners have a potential in academic (Malik, Rehman \& Hanif, 2012: 147).

\subsection{Literacy and Numeracy Curriculum for Children with Special Needs}

Hallahan \& Kauffman (2003) suggests that “... curriculum modification is important in the education of students with significant cognitive disabilities: adapting the curriculum and augmentative the curriculum" (p.415-418). Adaptation in this context refers to teaching and learning presentation, and how student responses and involvement in learning. Adaptation is the essence of one of the aspects of the implementation of inclusion. Furthermore, the curriculum augmentative acts with no change in the curriculum, but adds to the learning strategy. Special needs children are found to have problems when they are given a lot of information including the use of paper-pencil form. They are supposed to be connected and internalized through creative activities to meet their unique needs in order to achieve success in learning. Any teaching and learning strategies are supposed to be able in increasing the self-concept (self-esteem) and ability to learn (aptitude for learning), and the increase was supported by the provision of educational programs individualized (Hobson \& Vu, 2015) . Sugapriya \& Ramachandran (2011) stated that “...audio-visual materials, as integral part of teaching-learning situations help to bring about permanent and meaningful experience" (p. 948). Najma, Ghazala \& Rubina (2012) stated that "...the majority of slow learners are benefited from academic interventions implemented in various ways such as drama, playing the role of poetry and story readings" (p.147).

\subsection{Some Pedagogical Strategies in Teaching Numeracy and Literacy}

Sangeeta Chauhan (2011: 282-286) suggest the following elements in teaching and learning for slow learners: motivation, individual attention, restoration and development of self-confidence, elastic curriculum, remedial instruction, healthy environment, periodical medical check-up, and special methods of teaching. Rastogi (1978) and Narayana Rao (1987) suggest the following systematic for effective teaching and learning (1) teaching content should be carefully planned by taking into account the capacity of the student's mind, purpose, level of experience and education of students; (2) the length of lessons; (3) slow learners are able to capture concrete ideas rather than abstract ideas, so the use of audio-visual aids is necessary; (4) teachers should realize the fact that friendly approach is enabling the remedial teaching; (5) focusing on social skills and confidence level among slow learners, and stressing the effectiveness of the use of art, music, and drama; (6) teacher are supposed to prepare the most important aspect to be taught, repeated and reviewed; and (7) there is an optimal guarantee of human resources specially arranged for slow learners. 


\subsection{Research Objectives}

The current study explored challenges faced by children with special needs to improve their numeracy and literacy rates. The study also explored the most frequent pedagogical strategies to support special need children in improving their level of literacy and numeracy.

\section{Methodology of Research}

This is an exploratory study focusing on the challenges or obstacles faced by children to improve their literacy and numeracy rates; as well as the most frequent pedagogical strategies to improve literacy and numeracy rates children with support needs. Data was collected by using a focus group interview and observation techniques. An interview protocol and checklist forms were developed and validated by expert review. A total of 20 teachers (10 language teachers and 10 mathematic teachers) have been participated in this study. Sample of this study was students with learning difficulties (intellectual difficulties) who obtained poor grades in mathematical and language subjects. They also were labeled to be slow learners in an Indonesian socio-cultural context. They were mainly selected based on their performance in those subjects. They were excluded from ordinary groups of students to ensure teaching and learning is going efficiently. They were grouped in remedial classes for improving literacy and numeracy. Interview data was recorded, transcribed and coded independently by three coders. Inter-rater reliability scores is $80 \%$ indicating that the coders are agreed with the codes identified. Data from checklist forms were also reviewed and agreed by coders.

\section{Results and Discussion}

\section{Numeracy and Literacy Problems}

Findings show that most students have a difficulty in reading, writing and counting. For instance, there are twelve situations lead to the numeracy problems among special need children as reported by 20 teachers. All teachers reported that children from the three groups have difficulties to count up to 1000. Indeed, children from group 1 faced problems in numeracy as they are able to count to ten only.

\subsection{Numeracy Problems Faced by Special Need Children as Reported by Teachers}

\section{Problems faced by teachers from group 1 in numeracy}

Teachers from group 1 reported that most students are able to count up to 10 only. They also are found to count while jumping and able to add up to 10 only. The teachers also reported that slow learner's children can use operation with reduced numbers also only up to 10; still use fingers in calculating numbers. They also found unable to count more than 10 and for operation up to 50; just have not been able to reach the standard grade number 100. Some of them are reported not knowing the numbers at all. The children also tend to using fingers to count to ten, but when more than ten using a stick. The teacher reported that a subtraction operation only until the number five, the children use image and sticks to help them in numeracy, counting more than 10 with a series of short stacks and they likely to counting the number 10 on the lines that are crossed.

\section{Problems faced by teachers from group 2 in numeracy}

The challenges reported by the teachers from group 2 are the most students able to count up to 1000 but still have problems and the students usually needs assistance and guidance to solve mathematical task. The students also face difficulty in performing arithmetic operations of multiplication. The teachers reported that students have problems to solve mathematical operations with large numbers. They are also found often forgotten when calculating the multiplication and calculating the numbers 100 and 500 in the wrong sequence (count often jumping). The teachers described this group of students are unable to understand multiplication and division and some of them are not able to completely add, subtract, multiply, and divide.

\section{Problems faced by teachers from group 3 in numeracy}

Teachers from group 3 described that most students are able to multiply up to 50; able to solve divide operation up to 100 and sum up to 50 . They are also found to be helped by creating a series of lines to be deducted. The teachers reported that students have problems in multiplication and divide and are likely to operating the division with the help of a 'fence'. Students are also having an ability to operate a number of good sum, subtraction, multiplication, division with a cumulative figure below standard, that is only capable of up to 50, and sometimes only to 30

Based on the numeracy problem faced by special need children that reported by the teachers from group 1, group 2 and group 3, shows that the majority of learners have problems to count and solve mathematical operations. They also had difficulties in multiplication, subtraction and divide. 


\subsection{Literacy Problems faced by Special Need Children as Reported by Teachers}

\section{Problems faced by teachers from group 1 in literacy}

Teachers from group 1 reported that most students are still have not been able to memorize the letters a through $\mathrm{z}$. They also are found able to read certain words and mostly at the stage of spelling words. The teachers also described that these children are tends to spells per-syllable and unable to pronounce words correctly.

\section{Problems faced by teachers from group 2 in literacy}

The challenges reported by the teachers from group 2 are the students are mostly problems with pronunciation and they are difficult to read complex words. They are also difficult to read a long word, letters and often reduces the letters in a sentence. Lastly, the students are still read haltingly.

\section{Problems faced by teachers from group 3 in literacy}

Teachers from group 3 described that most students are able to read the sentence slowly and repeated and substandard which the students are at the stage of spelling words. However, they are found to have problems with comprehension. Teachers also reported that children have difficulty in reading words with consonant.

Most teachers reported that children have difficulties to memorize the alphabetic, pronounce some words, read complex sentences and comprehend the reading. It also shows that the majority of students have problems to read complex words. They also have problems to master comprehension. Some of them face problems in spelling.

\subsection{Writing Problems faced by Special Need Children as Reported by Teachers}

Problems faced by teachers from group 1 in writing

Teachers from group 1 reported that most students are often reversed in writing between the letters $b$ and $d ; p, m$, $\mathrm{n}, \mathrm{u}$ and $\mathrm{v}$ and they are also unable to distinguish the letters that looks almost like $\mathrm{b}$ and $\mathrm{d} ; \mathrm{m}$ and $\mathrm{n}$. It also found that the children faced difficulties to write words correctly. Most of them are also dictated letter by letter when asked to write. The teacher also stated that students are difficult to write and some of them did not want to write.

\section{Problems faced by teachers from group 1 in writing}

The challenges reported by the teachers from group 2 are students difficult to write words correctly and often reduce letters. The students also found unable to write as dictated teacher. The teachers clarify that students also unable to assemble letters into words.

\section{Problems faced by teachers from group 3 in writing}

The students from group 3 as address by the teachers is they found to have problems to form words and faced troubles with dictation. The students are also make repetition constantly when writing sentences.

The current study reveals that children have difficulties to write letters, identify words and distinguish the similar letters such as $\mathrm{b}$ and $\mathrm{d}, \mathrm{m}$ and $\mathrm{n}$ and etc. It shows that the most children have problems to write a correct word. This has a link with their abilities to read and read.

Wehmeyer, Hughes, et. al. (Hallahan \& Kauffman, 2003: 415-428) have suggested two levels of curriculum modification as important in the education of students with significant cognitive disabilities: adapting the curriculum and augmentative the curriculum. Sangeeta Chauhan (2011: 282-286) suggest that motivation, individual attention, restoration and development of self-confidence, elastic curriculum, remedial instruction, healthy environment, periodical medical check-up, and special methods of teaching. Some of the strategies used by teachers to help slow learners including exploring student's potential and the use of books and other learning resources that facilitate learning for children with special needs (Ahmad, Awang \& Yunus, 2015). Other strategies include,using media images to make it easier to learn, explained orally and repeatedly, an example by modelling, use media that can be touched or palpated, directly asked to ensure understanding can be captured, call the name of the child to pay attention, allow children to use various tools, encourage other students to help each other, support children in many ways, make sure slow learners sitting in the front row, give extra lessons after school time, provide remedy, assign homework that is simpler than with other students, reduction of duties, providing easier question to slow learners, providing assistance to slow learners, reading assistance, help slow learners to write, giving more time to the slow learners, provides a place for slow learners, provide tasks that can be corrected by slow learners andask parents to pay more attention to children learning.

The Most Frequent Pedagogical Strategies Used by Teachers

There are several strategies used by teachers in supporting and teaching children to improve literacy and 
numeracy.

The often strategies used include motivate children by expanding their real potentials, use suitable teaching aids, use media and visuals while teaching, repeat instructions, touchable media and teaching aids, socio-interaction with children, talk to children in a polite manner, provide many examples and allow children to use various learning objects.

The teacher also reported the seldom strategies that practiced by them towards the children which are slow learners by encourage children to help others, ask student to pay attentions, ensure children with special needs to stay at the first row in a classroom, provide extra teaching period, punish them, provide easy homework, limited tasks for children with special needs, easy problems solving tasks and support children to finish their works.

The teachers also sometimes applied the following strategies to deal with these children in their learning by help children in writing, help children in reading, extra time for children with special needs, special place for children with special needs, provide simple tasks, ask parents to pay attention to their children, discuss with parents, step-by-step guidance and provide tasks according to their levels.

\section{Conclusions}

Teaching language (literacy) and mathematical operations (numeracy) for children with support needs requires a unique pedagogical strategy. It has been found in this study that those children portrayed different types of supports. Generally, the majority of them faced difficulties in spelling, reading complex words, and write sentences. They also need to be supported in counting, solving subtraction, doing multiplication and divide. Although various pedagogical strategies have suggested in the past, teachers' competences and creativity are integral elements determining the successfulness of teaching literacy and numeracy. Realising the importance of these elements, teachers from the current study have carried out at least 27 teaching activities. It should be noted that those activities are common practice in teaching children with special needs. The fact that most children in the current study face challenges in literacy and numeracy. Therefore, rethinking of a new pedagogical strategy for improving literacy and numeracy children with special needs is needed. The new pedagogical strategy should be focusing on teachers; competences, pedagogical content knowledge, culturally responsive pedagogy, socio-cultural and values of children, and a new curriculum design. However, due to insufficient data from the current study to propose an alternative for a new pedagogical strategy, further study in the future in order to design and develop models for pedagogical strategies is needed.

\section{Recommendations}

The current study recommends several actions for improving literacy and numeracy. Firstly, a special curriculum for slow learners is required. The main focus should be given to the basic skills in literacy and numeracy. 'Evaluation for learning' should be the more important than 'evaluation of learning' for this group. Secondly, specific modules to support the existing teachers in gaining specific skills are really needed. At the same time, teachers' recruitment for tackling such group should be designed professionally. Finally, enhancing students' potential is supposed to be the integral part of education for children with special needs. A new pedagogical approach may be developed by implementing these suggestions.

\section{Acknowledgement}

I would like to thanks the Yogyakarta State University, Indonesia for providing supports and encouragements for me to carry out the research successfully. Special thanks to the National University of Malaysia for helping me to ensure the research output is publishable.

\section{References}

Ahmad, A. R., \& Awang, M. M. (2016). Culturally Responsive Pedagogy: Socio-Educational Support and Community Engagement for Educational Development of Aboriginal Students. The New Education Review, 43, 147-157.

Ahmad, A. R., Awang, M. M., \& Yunus, T. M. (2015). Senior teachers' perception on the roles and responsibilities of middle managers in schools. European Journal of Scientific Research, 132(3), 278-291.

Awang, M. M. et al. (2013). Students' Attitudes and Their Academic Performance in Nationhood Education. International Education Studies, 6(11), 21-28.

Berns, R. M. (2004). Child, Family, School, Community. Belmont: Thomson Learning.

Butler, F. M., Miller, S. P., Lee, K., \& Pierce, T. (2001). Teaching mathematics to students with mild-to-moderate mental retardation: A review of the literature. Mental Retardation, 39(1), $20-31$. 
https://doi.org/10.1352/0047-6765(2001)039<0020:TMTSWM>2.0.CO;2

Gall, M. D., Gall, J. P., \& Borg, W. R. (2003). Educational Research An Introduction. Boston: Pearson Education.

Hallahan, D. P., \& Kauffman, J. M. (2003). Exceptional learners: Introduction to special education (9th ed.). Boston: Allyn and Bacon.

Hobson, S., \& Vu, J. (2013). There is enough time: Accounting for each student's learning trajectory and identity development needs with proleptic-ethnodrama. Journal of Adolescent and Adult Literacy, 58(5), 397-406. https://doi.org/10.1002/jaal.367

Kauffman, J. M., \& Hallahan, D. P. (2011). Hand book of Special Education. New York: Routledge.

Kurtts, S. A. (2006). Universal design for learning in inclusive classrooms. Elctronic Journal for Inclusive Education, 1(10).

Malik, N. I., Rehman, G., \& Hanif, R. (2012). Effect of Academic Interventions on the Developmental Skills of Slow Learners. Pakistan Journal of Psychological Research, 27(1), 135-151.

Malik, S. (2009). Effect of Intervention Training on Mental Abilities of Slow Learners. International Journal Education Science, 1(1), 61-64.

Meynert, M. J. (2014). Inclusive Education And Perceptions Of Learning Facilitators Of Children With Special Needs in a School In Sweden. International Journal Of Special Education, 29(2).

OECD. (2015a). Education in Indonesia. Retrieved May 5, 2016, from http://www.adb.org/sites/default/files/publication/156821/education-indonesia-rising-challenge.pdf

OECD. (2015b). Education Policy Outlook: Poland. Retrieved May 5, 2015, from http://www.oecd.org/edu/POL-country-profile.pdf

Puccini, A. M., Puccini, M., \& Chang, A. (2013). Acquiring educational access for neurodiverse learners through multisensory design principles. In J. P. Hourcade (Ed.), Proceedings of the 12th International Conference on Interaction Design and Children (pp. 455-458). New York, NY: ACM. https://doi.org/10.1145/2485760.2485848

Quinn, R. (2011). Literacy and Numeracy for Learning and Life. Dublin: Department of Education and Skills.

Rosenblatt, K., Walker, Z., \& McMahon, D. (2015). Understanding the impact and importance of educational games for students with disabilities. In R. Lamb, \& D. McMahon (Eds.), Educational and Learning Games: New Research. New York: Nova Publishing Inc.

Sangeeta Chauhan, M. S. (2011). Slow Learners: Their psychology and educational programmes. International Journal of Multidiciplinary Research, 1(8), 279-289.

\section{Copyrights}

Copyright for this article is retained by the author(s), with first publication rights granted to the journal.

This is an open-access article distributed under the terms and conditions of the Creative Commons Attribution license (http://creativecommons.org/licenses/by/4.0/). 